\title{
Trajectories for mood states during a multi-session neurofeedback training intervention in major depressive disorder
}

David M.A. Mehler ${ }^{1,2,3}$, Stefanie L. Kunas ${ }^{1,4}$, Moses O. Sokunbi ${ }^{5}$, Rainer Goebel ${ }^{6,7}$, David E.J. Linden ${ }^{1,2,8}$

${ }^{1}$ School of Psychology, Cardiff University Brain Research Imaging Centre (CUBRIC), Cardiff, United Kingdom

${ }^{2}$ MRC Centre for Neuropsychiatric Genetics and Genomics, School of Medicine, Cardiff University, Cardiff, United Kingdom

${ }^{3}$ Department of Psychiatry, University Hospital Münster, Germany

${ }^{4}$ Department of Psychiatry and Psychotherapy, Charité Universitätsmedizin Berlin, Berlin, Germany

${ }^{5}$ School of Allied Health Sciences, Faculty of Health and Life Sciences, De Montfort University, The Gateway, Leicester, LE1 9BH, UK.

${ }^{6}$ Faculty of Psychology and Neuroscience, Maastricht University, Universiteitssingel 40, Maastricht, 6229 ER, The Netherlands.

${ }^{7}$ Brain Innovation B.V., Oxfordlaan 55, Maastricht, 6229 EV, The Netherlands.

${ }^{8}$ School for Mental Health and Neuroscience, Faculty of Health, Medicine and Life Sciences, Maastricht University, The Netherlands

Highlights

- Mood profiles in major depressive disorder patients show different trajectories.

- Within-session effects dominated total mood disturbance and subscales depression and tension.

- Changes in total mood disturbance related to physician rated changes in depressive symptom load. 


\section{Abstract}

\section{Background}

Non-invasive neurofeedback training is currently explored as a potential add-on therapy to treat patients suffering from major depressive disorder, and first trials show promising clinical effects. The temporal evolution of therapeutic change, however, remains unclear.

Methods

Profile of mood states (POMS) questionnaire ratings were collected immediately before and after five sessions of real-time fMRI neurofeedback training (rt-fMRI-NFT) in a randomised controlled trial (RCT). Data were analysed for within and between treatment sessions effects.

Results

Trajectories of mood profiles varied between subscales. Total mood disturbance and the subscales depression and tension showed both within and between treatment sessions effects, although within-session effects were descriptively larger.

\section{Limitations}

The sample size was relatively small owed to the current state of the rt-fMRI-NFT field. No data from a sham-neurofeedback control group was available.

\section{Conclusions}

The presented data provides a better understanding of when changes in mood states occur. The POMS questionnaire allows monitoring rapid and slowly evolving changes in mood states and can thus inform future study designs for neuromodulation and psychological interventions for mental disorders.

\section{Keywords}

Depression; major depressive disorder; neurofeedback; Randomized Controlled Trial; complex intervention

\section{Abbreviations}

HDRS, Hamilton Depression Rating Scale; POMS, Profile of Mood States; RCT, Randomized controlled trial; VS-MPR, Vovk-Sellke Maximum p-ratio; rt-fMRI-NFT, real-time functional magnetic resonance imaging; TMD, Total Mood Disturbance. 


\section{Introduction}

Major depressive disorder is considered the largest contributor to disability globally, and about one third of patients do not respond to available pharmacological and non-pharmacological treatments (World Health Organization, 2017). Non-invasive neurofeedback training has gained interest as a potential add-on therapy for depressed patients and other psychiatric conditions (Arns et al., 2017). Neurofeedback training paradigms traditionally employ mental imagery strategies that are often inspired by emotion regulation techniques similar to those used in cognitive behavioural therapy. In most paradigms, patients receive immediate visual feedback from neural substrates (e.g. limbic structures) that are activated during this mental practice and hence engage in a form of positive reinforcement learning. A recent systematic review found that neurofeedback training may yield substantial effects in depressed patients with up to $40 \%$ improvements in depressed symptoms compared to baseline (Trambaiolli et al., 2021). However, current literature has thus far reported clinical changes as sum scores over a period of several weeks. It thus remains unclear to which extent changes in different symptoms occur within or between training sessions.

Standardised clinical depression scales, as commonly employed in intervention studies (e.g. the patient-rated Beck Depression Inventory or the clinician-rated Hamilton Depression Rating Scale; HDRS), are only suited to measure symptom changes between training sessions because they require assessment intervals of at least one or two weeks, respectively. Another instrument, which can be used at a higher frequency to measure changes in current mood states - for instance within a neurofeedback training session - is the Profile of Mood States (POMS) questionnaire (McNair, 1971). The POMS questionnaire comprises ratings for the subscales tension (POMST), depression (POMS-D), anger (POMS-A), confusion (POMS-C), fatigue (POMS-F) and vigour (POMS-V). It is an easy-to-use self-rated questionnaire that has shown high predictive validity as a screening instrument for MDD patients (Patterson et al., 2008). Moreover, it has satisfactory test-retest reliability, and internal consistency is satisfactory (Nyenhuis et al., 1999) and POMS-D correlates strongly with the well-established self-rated Beck depression inventory II (Griffith et al., 2005) POMS is thus well suited to monitor both within and between session treatment effects of complex intervention in psychiatric populations such as neurofeedback training in depressed patients.

Previous feasibility neurofeedback studies conducted with depressed patients have reported within session (Young et al., 2014) as well as within and between session improvements in total 
mood disturbance (TMD) ratings and its depression subscale (Linden et al., 2012). However, interpretation of these data is limited given the exploratory nature of these feasibility studies, the small number of training sessions, short duration of the intervention (max. 4 weeks) and the relatively small number of participants. Moreover, exploring the trajectories for different mood subscales is desired for a better understanding of therapeutic mechanisms. For instance, while ratings on the subscale "depression" may change mostly early in the intervention, changes on another subscale such as "anger" may show a different trajectory. Lastly, this question is

pertinent to improve study designs with regards to the number of training sessions needed to target specific symptoms (Trambaiolli et al., 2021). We therefore need a fine-grained temporal analysis of symptom change based on data from larger randomised clinical trials (RCTs) that capture a longer time period.

In this short communication we present POMS data collected in the context of a previously published RCT of real-time functional magnetic resonance imaging (rt-fMRI) neurofeedback training in medicated depressed individuals (Mehler et al., 2018). We aimed to explore when changes occurred in different subscales and whether within-session and between-session changes in mood scale ratings interacted with the number of training sessions.

\section{Methods}

Intervention: POMS data was obtained from an rt-fMRI neurofeedback training RCT conducted in medicated, moderately depressed (sample mean HDRS-17 $=19.5$ ) patients who $(\mathrm{N}=32$ ) completed five training sessions (Mehler et al., 2018). The study was approved in January 2012 by the South East Wales Research Ethics Committee and registered in February 2012 (NCT01544205). POMS data was obtained immediately before and after each training session. The trial design consisted of a main experimental group $(\mathrm{N}=16)$ that engaged in positive mental imagery while receiving visual feedback from limbic brain areas as well as an active control group $(\mathrm{N}=16)$ that imagined relaxing scenes and received feedback from higher visual cortices, including the parahippocampal place area. The interval between training sessions varied slightly between patients and was on average 1-2 weeks for session 1-4 and about 4-6 weeks for session 5 (which was completed on average 12 weeks after session 1). Clinical findings reported previously suggested that both groups showed substantial improvements to a similar extend with over $40 \%$ reduction a standardised clinical rating scale (HDRS-17). For further clinical and technical details of the RCT, please refer to (Mehler et al., 2018). 
Measures of current mood state and statistical analysis: The POMS Standard Form (McNair, 1971) contains sixty-five words or statements that describe feelings (e.g. "Now I have felt tense.") of either depression, tension, anger, confusion, fatigue or vigour. Individuals circle the number that correspond to their current mood state $(0=$ "not at all", $1=$ "a little", $2=$ "moderately", 3 = "quite a bit", 4 = "extremely"). The higher the score that is obtained on this test, the greater the Total Mood Disturbance (TMD) that is experienced. Following neurofeedback training, we expected to observe a decrease in TMD and all subscale scores (except for an expected increase in POMS-V).

Statistical analysis: Because no group difference for clinical improvements was found for the intervention, the effectiveness of training protocols was considered comparable. Hence, for the exploratory follow-up analyses presented here, POMS data was pooled across experimental groups to increase the sample size. Due to missing data of the last training session, one subject was removed from analyses leaving a total sample of 31 patients. Pre- and Post-session TMD and subscale ratings for each of the five neurofeedback training sessions were submitted to $5 \times 2$ repeated-measures analysis of variance (ANOVAs), resulting in six analyses. All analyses and plots were carried out using the open-source statistical software package JASP version 0.12.2 (Love et al., 2019). Besides F- and p-values, we also report effect sizes (partial eta squared; $\eta^{2}$ ) and the Vovk-Sellke Maximum p-ratio (VS-MPR), which expresses how much more likely data occurred under alternative compared to null hypothesis (Sellke et al., 2001; Vovk, 1993). To explore whether significant effects already occurred after the first training session, differences between pre and post assessment of session 1 for TMD and POMS-D for all 32 patients were submitted to one-sample t-tests. To explore whether changes on the TMD or the depression subscale reflected changes in depressive symptoms as measured by a standardised clinical depression scale, difference scores (between the pre assessment of session 1 and post assessment of session 5) were correlated with difference scores of the 17-item version of the Hamilton Depression Rating Scale (HDRS-17) that constituted the main clinical outcome measure of the RCT.

\section{Results}

Repeated measures ANOVAs for TMD and the subscales POMS-D, POMS-T and POMS-C found both significant within- and between- session effects (Table 1). Further, effect sizes suggested that within-session effects were descriptively larger than between-session effects. The other subscales showed different profiles: for POMS-A, we found only a significant within 
session effect, for POMS-F a significant between session effects, and for POMS-V a between session effect and an interaction of within-session and between-session effects.

\begin{tabular}{|c|c|c|c|c|c|c|c|}
\hline Cases & $\begin{array}{l}\text { Sum of } \\
\text { Squares }\end{array}$ & df & Mean Square & $\mathbf{F}$ & $\mathbf{p}$ & VS-MPR & $\eta_{p}^{2}$ \\
\hline \multicolumn{8}{|l|}{ TMD } \\
\hline WS & 13032.581 & 1 & 13032.581 & 30.860 & $<.001$ & 6186.096 & 0.507 \\
\hline BS & 20826.729 & 4 & 5206.682 & 6.690 & $<.001$ & 564.964 & 0.182 \\
\hline $\mathrm{WS} * \mathrm{BS}$ & 2849.065 & 4 & 712.266 & 1.958 & 0.105 & 1.552 & 0.061 \\
\hline \multicolumn{8}{|l|}{ POMS-D } \\
\hline WS & 2281.552 & 1 & 2281.552 & 48.326 & $<.001$ & 225899.180 & 0.617 \\
\hline BS & 2056.981 & 4 & 514.245 & 6.150 & $<.001$ & 270.598 & 0.170 \\
\hline $\mathrm{WS} * \mathrm{BS}$ & 185.626 & 4 & 46.406 & 1.275 & 0.284 & 1.029 & 0.041 \\
\hline \multicolumn{8}{|l|}{ POMS-T } \\
\hline WS & 480.632 & 1 & 480.632 & 15.239 & $<.001$ & 97.286 & 0.337 \\
\hline $\mathrm{BS}$ & 533.045 & 4 & 133.261 & 3.567 & 0.009 & 8.904 & 0.106 \\
\hline $\mathrm{WS} * \mathrm{BS}$ & 53.948 & 4 & 13.487 & 0.638 & 0.636 & 1.000 & 0.021 \\
\hline \multicolumn{8}{|l|}{ POMS-A } \\
\hline WS & 531.729 & 1 & 531.729 & 19.819 & $<.001$ & 370.120 & 0.398 \\
\hline $\mathrm{BS}$ & 127.245 & 4 & 31.811 & 1.056 & 0.382 & 1.000 & 0.034 \\
\hline $\mathrm{WS} * \mathrm{BS}$ & 102.690 & 4 & 25.673 & 1.476 & 0.214 & 1.115 & 0.047 \\
\hline \multicolumn{8}{|l|}{ POMS-C } \\
\hline WS & 57.923 & 1 & 57.923 & 4.586 & 0.040 & 2.834 & 0.133 \\
\hline $\mathrm{BS}$ & 718.110 & 4 & 179.527 & 8.614 & $<.001$ & 7747.912 & 0.223 \\
\hline $\mathrm{WS} * \mathrm{BS}$ & 26.303 & 4 & 6.576 & 0.579 & 0.679 & 1.000 & 0.019 \\
\hline \multicolumn{8}{|l|}{ POMS-F } \\
\hline WS & 25.552 & 1 & 25.552 & 0.856 & 0.362 & 1.000 & 0.028 \\
\hline $\mathrm{BS}$ & 567.400 & 4 & 141.850 & 3.675 & 0.007 & 10.179 & 0.109 \\
\hline $\mathrm{WS} * \mathrm{BS}$ & 122.239 & 4 & 30.560 & 1.593 & 0.181 & 1.190 & 0.050 \\
\hline \multicolumn{8}{|l|}{ POMS-V } \\
\hline WS & 76.503 & 1 & 76.503 & 2.319 & 0.138 & 1.345 & 0.072 \\
\hline BS & 349.516 & 4 & 87.379 & 3.616 & 0.008 & 9.456 & 0.108 \\
\hline $\mathrm{WS}$ * BS & 233.077 & 4 & 58.269 & 3.403 & 0.011 & 7.274 & 0.102 \\
\hline
\end{tabular}

Table 1 Repeated measure ANOVA results for TMD and subscales. WS = within session, BS = between session, $\mathrm{df}=$ degrees of freedom, VS-MPR $=$ Vovk-Sellke Maximum p-ratio. 


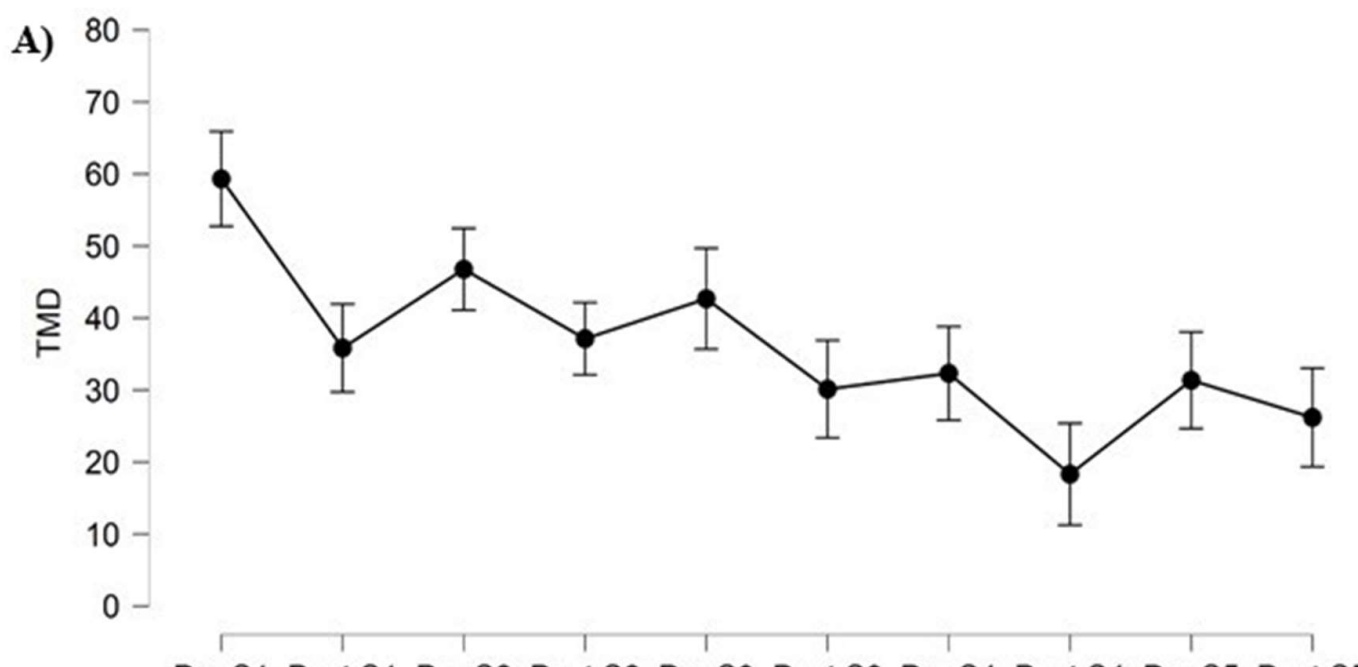

Pre S1 Post S1 Pre S2 Post S2 Pre S3 Post S3 Pre S4 Post S4 Pre S5 Post S5

B)

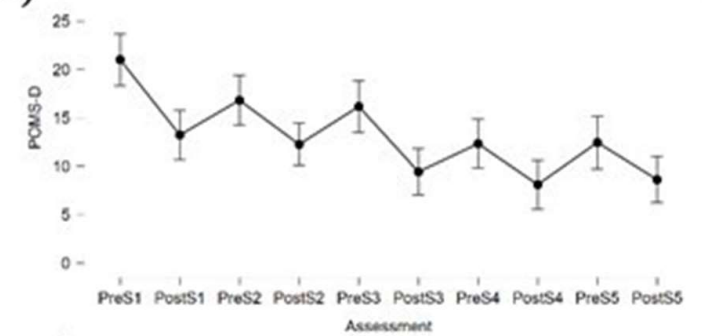

D) ${ }_{10}^{12}$
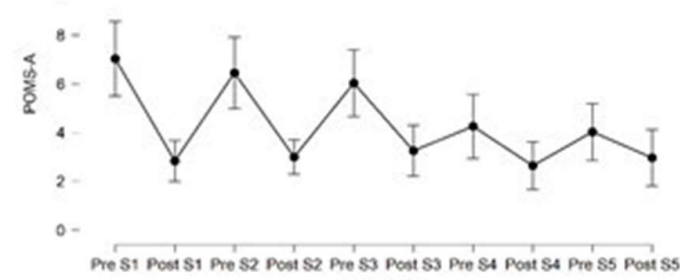

F)

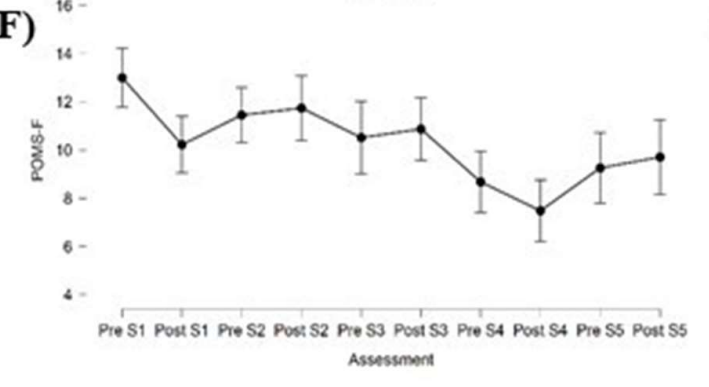

Assessment

C) ${ }^{18-}$

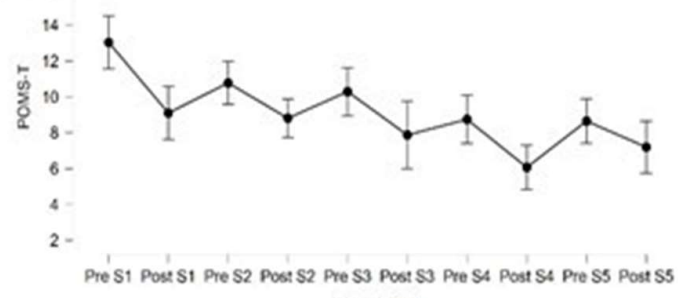

E)

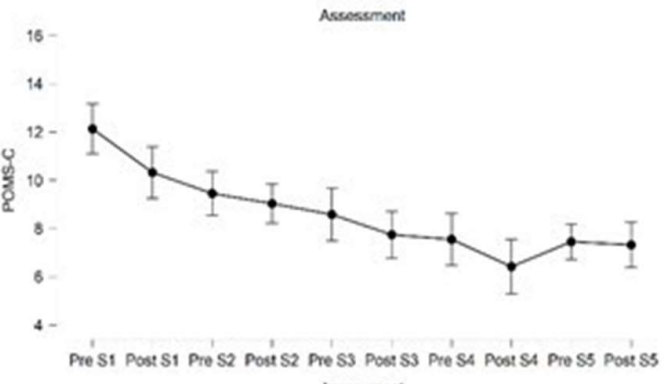

G) Assussmete

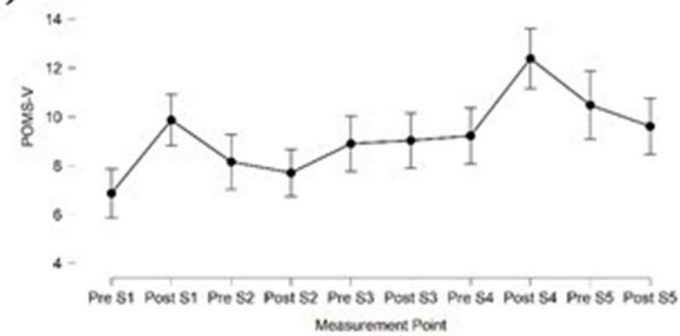

Figure 1 Trajectory of sample mean POMS TMD scores and its subscales for pre and post assessments of neurofeedback training sessions one (S1) to five (S5). Error bars show standard error of the mean.

The trajectories for TMD ratings and POMS-D, POMS-T and POMS-A showed a sawtoothlike pattern such that major changes occurred within training sessions but reversed to some extent until the beginning of the next training session (Figure 1 A-D). Moreover, descriptively 
the largest improvements on these scales seem to have occurred during the first three training sessions with about $50 \%$ reduction in ratings when comparing pre-assessment scores of session 1 with post-assessment scores of session 3 (Table S1). In contrast, the trajectory for POMS-C showed a nearly monotonic decrease. No distinct trajectory pattern was observed for POMS-F and POMS-V. Exploratory t-tests confirmed that already after one training session significant reductions were found for TMD and POMS-D ( $\mathrm{t}_{31}=4.314, \mathrm{p}<0.001$, Cohen's $\mathrm{d}=0.763 \pm 95 \%$ Confidence Interval [0.36-1.15] and $t_{31}=4.164, \mathrm{p}<0.001$, Cohen's $d=0.74 \pm 95 \%$ Confidence Interval [0.34-1.12], respectively). Lastly, we found that changes between the pre assessment at session 1 and post assessment at session 5 in TMD as well as POMS-D correlated with changes in the HDRS-17 $(\mathrm{r}=0.367, \mathrm{p}=0.042$ and $\mathrm{r}=0.356, \mathrm{p}=0.049$, respectively). 


\section{Discussion and conclusion}

Longitudinal multiple session data from a rt-fMRI neurofeedback training RCT in patients diagnosed with major depressive disorder patients suggested that reductions in total mood disturbance (TMD) occurred both within and between sessions. Rapid within session effects were larger and mostly driven by improvements on the subscale depression, and already occurred after the first neurofeedback session. Similar trajectories were observed for the subscales tension and confusion. Altogether, the largest improvements for TMD, POMS-D POMS-T and POMS-A were observed after two to three training sessions and these effects were largely preserved until the last training session at week 12 (Figure 1A-D and Table S1).

The presented findings suggest that one single rt-fMRI-NFT session may already result in significant improvements in total self-ratings related to mood disturbance and depression. They complement clinical findings reported from an rt-fMRI-NFT RCT conducted in moderately depressed patients (Young et al., 2017) such that substantial changes in mood states including depression may already occur after the first two training sessions. Noteworthy, visual feedback was not shown to patients during the third training session because it served as a transfer session to test whether patients had learned to up-regulate target regions. Although the neural data reported in (Mehler et al., 2018) suggested that patients activated target regions less compared to the other training sessions, improvements on the TMD as well as the subscale ratings for depression and tension were comparable to the second training session when feedback was

provided. Indeed, reward expectancies as well as mental imagery training already have affect psychological states and likely contribute to unspecific therapeutic effects in complex interventions such as neurofeedback training (Ros et al., 2020; Sorger et al., 2019). The presented findings are limited by the relatively small sample size, which is typical for phase II RCTs and reflects the current state of the rt-fMRI-NFT field (Tursic et al., 2020). Moreover, the trial design employed an active control group that engaged in veridical neurofeedback training and thus showed comparable therapeutic effects compared to the main experimental group, see (Mehler et al., 2018) for a detailed discussion. For this reason, data was pooled across groups to increase statistical sensitivity. The available sample thus did not allow controlling for unspecific neurofeedback related effects such as reward and motivation. For the future it will be of interest to compare changes in TMD and its subscales in complex interventions such as neurofeedback training that employ a different type of control condition (for instance standard care or a form of sham treatment). Moreover, it will be of interest to investigate to which extend 
mood improvements occurring during a previous training session revert until the following. Investing such rebound will require more systematically planned intervals between training sessions and a larger sample size.

To conclude, the present findings shine further light on the temporal evolution of different mood states during a multi-session neurofeedback intervention in medicated, moderately depressed patients. Within session effects on mood profiles were larger than between session effects. Moreover, substantial improvements occurred already after the first two to three sessions and prevailed for several weeks. We encourage intervention studies to employ easy-to-use multidimensional mood state measures such as the POMS to explore both fast and slowly evolving changes of different mood states. The temporal evolution of therapeutic change is not just relevant for a better understanding of dosing regimens for neuromodulation interventions such as neurofeedback but also more generally for psychological and other interventions in mental health.

\section{Declaration of interest}

DMAM receives payments for work as an independent consultant to a neurofeedback start-up company (Mendi Innovations AB). RG is CEO of Brain Innovation B.V. The remaining authors declare no competing interests.

\section{Funding}

This work was supported by Medical Research Council (grant G 1100629) to DEJL, a PhD studentship from Health and Care Research Wales to DMAM (HS/14/20, grant holder DEJL). DEJL and RG were PIs on the BRAINTRAIN consortium, supported by the European Commission under the Health Cooperation Work Programme of the 7th Framework Programme $\left(n^{\circ} 602186\right)$. 


\section{References}

Arns, M., Batail, J.-M., Bioulac, S., Congedo, M., Daudet, C., Drapier, D., Fovet, T., Jardri, R., Le-VanQuyen, M., Lotte, F., Mehler, D., Micoulaud-Franchi, J.-A., Purper-Ouakil, D., Vialatte, F., 2017. Neurofeedback: One of today's techniques in psychiatry? Encephale. 43, 135-145. https://doi.org/10.1016/j.encep.2016.11.003

Griffith, N.M., Szaflarski, J.P., Szaflarski, M., Kent, G.P., Schefft, B.K., Howe, S.R., Privitera, M.D., 2005. Measuring depressive symptoms among treatment-resistant seizure disorder patients: POMS Depression scale as an alternative to the BDI-II. Epilepsy Behav. 7, 266-272. https://doi.org/10.1016/j.yebeh.2005.05.004

Linden, D., Habes, I., Johnston, S., Linden, S., 2012. Real-time self-regulation of emotion networks in patients with depression. PLoS One 7, e38115.

Love, J., Selker, R., Jamil, T., Dropmann, D., Ly, A., Gronau, Q.F., Šmíra, M., Epskamp, S., Wild, A., Knight, P., Morey, R.D., 2019. JASP : Graphical Statistical Software for Common Statistical Designs 88. https://doi.org/10.18637/jss.v088.i02

McNair, D.M., 1971. Manual profile of mood states. San Diego: Educational \& Industrial testing service.

Mehler, D.M.A., Sokunbi, M.O., Habes, I., Barawi, K., Subramanian, L., Range, M., Evans, J., Hood, K., Lührs, M., Keedwell, P., Goebel, R., Linden, D.E.J., 2018. Targeting the affective brain-a randomized controlled trial of real-time fMRI neurofeedback in patients with depression. Neuropsychopharmacology 1-8. https://doi.org/10.1038/s41386-018-0126-5

Nyenhuis, D.L., Yamamoto, C., Lucheta, T., Terrien, A., Parmentier, A., 1999. Adult and geriatric normative data and validation of the profile of mood states. J. Clin. Psychol. 55, 79-86. https://doi.org/10.1002/(SICI)1097-4679(199901)55:1<79::AID-JCLP8>3.0.CO;2-7

Patterson, K., Young, C., Woods, S.P., Vigil, O., Grant, I., Atkinson, J.H., GROUP, A.T.H.N.R.C. (HNRC), 2008. Using neuroimaging to predict relapse to smoking: role of possible moderators and mediators. Int. J. Methods Psychiatr. Res. 17 Suppl 1, S78-S82. https://doi.org/10.1002/mpr

Ros, T., Enriquez-Geppert, S., Zotev, V., Young, K.D., Wood, G., Whitfield-gabrieli, S., Wan, F., Vuilleumier, P., Ville, D. Van De, Todder, D., Surmeli, T., Sulzer, J.S., Strehl, U., Sterman, M.B., Steiner, N.J., Sorger, B., Soekadar, S.R., Sitaram, R., Sherlin, L.H., Scharnowski, F., Schabus, M., Rubia, K., Scho, M., Rosa, A., Reiner, M., Pineda, J.A., Paret, C., Ossadtchi, A., Nicholson, A.A., Nan, W., Minguez, J., Micoulaud-Franchi, J.-A., Mehler, D.M.A., Lührs, M., Lubar, J., Lotte, F., 
Linden, D.E.J., Lewis-peacock, J.A., Lebedev, M.A., Kranczioch, C., Koush, Y., Konicar, L., Lanius, R.A., Ku, A., Kohl, S.H., Kober, S.E., Klados, M.A., Jeunet, C., Janssen, T.W.P., Huster, R.J., Hoedlmoser, K., Hirshberg, L.M., Heunis, S., Hendler, T., Hampson, M., Guggisberg, A.G., Guggenberger, R., Gninenko, N., Gharabaghi, A., Ridder, D. De, Davelaar, E.J., Congedo, M., Cavazza, M., Breteler, M.H.M., Brandeis, D., Bodurka, J., Birbaumer, N., Bazanova, O.M., Barth, B., Bamidis, P.D., Auer, T., Arns, M., Thibault, R.T., 2020. Consensus on the reporting and experimental design of clinical and cognitive-behavioural neurofeedback studies (CRED-nf checklist). Brain. https://doi.org/10.1093/brain/awaa009

Sellke, T., Bayarri, M., Berger, J.O., 2001. Calibration of $p$ values for testing precise null hypotheses. Am. Stat. 55, 62-71.

Sorger, B., Scharnowski, F., Linden, D.E.J., Hampson, M., Young, K.D., 2019. Control freaks: Towards optimal selection of control conditions for fMRI neurofeedback studies. Neuroimage 186, 256265. https://doi.org/10.1016/j.neuroimage.2018.11.004

Trambaiolli, L., Kohl, S.H., Linden, D.E.J., Mehler, D.M., 2021. Neurofeedback training in major depressive disorder: a systematic review of clinical efficacy, study quality and reporting practices. Neurosci. Biobehav. Rev. https://doi.org/10.1016/j.neubiorev.2021.02.015

Tursic, A., Eck, J., Lührs, M., Linden, D.E.J., Goebel, R., 2020. A systematic review of fMRI neurofeedback reporting and effects in clinical populations. Neurolmage. Clin. 28, 102496. https://doi.org/10.1016/j.nicl.2020.102496

Vovk, V.G., 1993. A logic of probability, with application to the foundations of statistics. J. R. Stat. Soc. Ser. B 55, 317-351.

World Health Organization, 2017. Depression and other common mental disorders: global health estimates. World Heal. Organ. 1-24. https://doi.org/CC BY-NC-SA 3.0 IGO

Young, K.D., Siegle, G.J., Zotev, V., Phillips, R., Misaki, M., Yuan, H., Drevets, W.C., Bodurka, J., 2017. Randomized Clinical Trial of Real-Time fMRI Amygdala Neurofeedback for Major Depressive Disorder: Effects on Symptoms and Autobiographical Memory Recall. Am. J. Psychiatry 174, 748-755. https://doi.org/10.1176/appi.ajp.2017.16060637

Young, K.D., Zotev, V., Phillips, R., Misaki, M., Yuan, H., Drevets, W.C., Bodurka, J., 2014. Real-time fMRI neurofeedback training of amygdala activity in patients with major depressive disorder. PLoS One 9. https://doi.org/10.1371/journal.pone.0088785 
Supplementary Information

\begin{tabular}{|c|c|c|c|c|c|c|c|c|c|c|}
\hline & $\begin{array}{l}\text { Pre } \\
\text { S1 }\end{array}$ & $\begin{array}{l}\text { Post } \\
\text { S1 }\end{array}$ & $\begin{array}{l}\text { Pre } \\
\text { S2 }\end{array}$ & $\begin{array}{l}\text { Post } \\
\text { S2 }\end{array}$ & $\begin{array}{l}\text { Pre } \\
\text { S3 }\end{array}$ & $\begin{array}{l}\text { Post } \\
\text { S3 }\end{array}$ & $\begin{array}{l}\text { Pre } \\
\text { S4 }\end{array}$ & $\begin{array}{c}\text { Post } \\
\text { S4 }\end{array}$ & $\begin{array}{l}\text { Pre } \\
\text { S5 }\end{array}$ & $\begin{array}{c}\text { Post } \\
\text { S5 }\end{array}$ \\
\hline \multicolumn{11}{|l|}{ TMD } \\
\hline $\begin{array}{l}\text { Mean } \\
\text { (S.D.) }\end{array}$ & $\begin{array}{l}59.5 \\
(36.0)\end{array}$ & $\begin{array}{l}35.4 \\
(33.6)\end{array}$ & $\begin{array}{l}47.2 \\
(31.2)\end{array}$ & $\begin{array}{l}37.3 \\
(27.5)\end{array}$ & $\begin{array}{l}43.2 \\
(38.5)\end{array}$ & $\begin{array}{l}30.3 \\
(37.1)\end{array}$ & $\begin{array}{r}33.0 \\
(35.8)\end{array}$ & $\begin{array}{l}18.1 \\
(38.7)\end{array}$ & $\begin{array}{l}31.4 \\
(37.3)\end{array}$ & $\begin{array}{r}26.2 \\
(38.0)\end{array}$ \\
\hline \multicolumn{11}{|l|}{ POMS-D } \\
\hline $\begin{array}{l}\text { Mean } \\
\text { (S.D.) }\end{array}$ & $\begin{array}{l}21.2 \\
(14.7)\end{array}$ & $\begin{array}{l}12.9 \\
(14.2)\end{array}$ & $\begin{array}{l}16.9 \\
(14.1)\end{array}$ & $\begin{array}{l}12.2 \\
(12.0)\end{array}$ & $\begin{array}{l}16.3 \\
(14.6)\end{array}$ & $\begin{array}{l}9.3 \\
(13.2)\end{array}$ & $\begin{array}{l}12.5 \\
(14.0)\end{array}$ & $\begin{array}{l}7.9 \\
(13.8)\end{array}$ & $\begin{array}{l}12.5 \\
(15.2)\end{array}$ & $\begin{array}{l}8.6 \\
(13.3)\end{array}$ \\
\hline \multicolumn{11}{|l|}{ POMS-T } \\
\hline $\begin{array}{l}\text { Mean } \\
\text { (S.D.) } \\
\text { POMS-A }\end{array}$ & $\begin{array}{l}6.8 \\
(8.5)\end{array}$ & $\begin{array}{l}2.8 \\
(4.6)\end{array}$ & $\begin{array}{l}6.3 \\
(8.1)\end{array}$ & $\begin{array}{l}3.0 \\
(3.8)\end{array}$ & $\begin{array}{l}5.9 \\
(7.6)\end{array}$ & $\begin{array}{l}3.2 \\
(5.7)\end{array}$ & $\begin{array}{l}4.2 \\
(7.2)\end{array}$ & $\begin{array}{l}2.6 \\
(5.4)\end{array}$ & $\begin{array}{l}4.0 \\
(6.5)\end{array}$ & $\begin{array}{l}3.0 \\
(6.4)\end{array}$ \\
\hline $\begin{array}{l}\text { Mean } \\
\text { (S.D.) }\end{array}$ & $\begin{array}{l}6.8 \\
(8.5)\end{array}$ & $\begin{array}{l}2.8 \\
(4.6)\end{array}$ & $\begin{array}{l}6.3 \\
(8.1)\end{array}$ & $\begin{array}{l}3.0 \\
(3.8)\end{array}$ & $\begin{array}{l}5.9 \\
(7.6)\end{array}$ & $\begin{array}{l}3.2 \\
(5.7)\end{array}$ & $\begin{array}{l}4.2 \\
(7.2)\end{array}$ & $\begin{array}{l}2.6 \\
(5.4)\end{array}$ & $\begin{array}{l}4.0 \\
(6.5)\end{array}$ & $\begin{array}{l}3.0 \\
(6.4)\end{array}$ \\
\hline \multicolumn{11}{|l|}{ POMS-C } \\
\hline $\begin{array}{l}\text { Mean } \\
\text { (S.D.) } \\
\text { POMS-F }\end{array}$ & $\begin{array}{l}12.2 \\
(5.7)\end{array}$ & $\begin{array}{l}10.3 \\
(5.9)\end{array}$ & $\begin{array}{l}9.5 \\
(5.0)\end{array}$ & $\begin{array}{l}9.1 \\
(4.5)\end{array}$ & $\begin{array}{l}8.6 \\
(5.9)\end{array}$ & $\begin{array}{l}7.7 \\
(5.3)\end{array}$ & $\begin{array}{l}7.6 \\
(5.9)\end{array}$ & $\begin{array}{l}6.4 \\
(6.2)\end{array}$ & $\begin{array}{l}7.5 \\
(4.4)\end{array}$ & $\begin{array}{l}7.3 \\
(5.2)\end{array}$ \\
\hline $\begin{array}{l}\text { Mean } \\
\text { (S.D.) } \\
\text { POMS-V }\end{array}$ & $\begin{array}{l}13.0 \\
(6.7)\end{array}$ & $\begin{array}{l}10.6 \\
(6.5)\end{array}$ & $\begin{array}{l}11.6 \\
(6.3)\end{array}$ & $\begin{array}{l}11.7 \\
(7.4)\end{array}$ & $\begin{array}{l}10.8 \\
(8.3)\end{array}$ & $\begin{array}{l}11.1 \\
(7.2)\end{array}$ & $\begin{array}{l}8.8 \\
(7.0)\end{array}$ & $\begin{array}{l}7.5 \\
(7.0)\end{array}$ & $\begin{array}{l}9.3 \\
(8.2)\end{array}$ & $\begin{array}{l}9.7 \\
(8.6)\end{array}$ \\
\hline $\begin{array}{l}\text { Mean } \\
\text { (S.D.) }\end{array}$ & $\begin{array}{l}6.7 \\
(5.5)\end{array}$ & $\begin{array}{l}9.6 \\
(5.9)\end{array}$ & $\begin{array}{l}7.9 \\
(6.3)\end{array}$ & $\begin{array}{l}7.6 \\
(5.3)\end{array}$ & $\begin{array}{l}8.6 \\
(6.4)\end{array}$ & $\begin{array}{l}8.8 \\
(6.4)\end{array}$ & $\begin{array}{l}8.9 \\
(6.5)\end{array}$ & $\begin{array}{l}12.2 \\
(6.8)\end{array}$ & $\begin{array}{l}10.5 \\
(7.8)\end{array}$ & $\begin{array}{l}9.6 \\
(6.4)\end{array}$ \\
\hline
\end{tabular}

Table S1 Mean and standard deviations (S.D.) of TMD and subscale ratings for pre- and post assessment of training sessions 1 to 5 . 